\title{
Erythrocytic inclusion body syndrome: a light and electron microscopic study of infected erythrocytes of chinook Oncorhynchus tshawytscha and coho O. kisutch salmon
}

\author{
Patty Michak $^{1}$, Charlie E. Smith ${ }^{2}$, Kathleen Hopper ${ }^{1}$ \\ 'Washington Department of Fisheries, Olympia, Washington 98504, USA \\ ${ }^{2}$ U.S. Fish \& Wildlife Service, Fish Technology Center, Bozeman, Montana 59715, USA
}

\begin{abstract}
Investigation of natural infections of viral erythrocytic inclusion body syndrome (EIBS) were conducted at Washington Department of Fisheries (WDF) salmon hatcheries. Comparisons were made of morphological changes seen in stained blood cells by light microscopy with those seen by electron microscopy, and it was determined whether erythrocytic inclusions were of viral origin. Blood was collected from 10 to 12 fish for each of 8 stocks of salmon. Blood smears and whole blood were processed for microscopic evaluation. By light microscopy infected erythrocytes typically had single, pale blue (Leishman-Giemsa stain) inclusions. Erythrocytes in many stages of development were common, and in some stocks immature erythrocytes accounted for 50 to $75 \%$ of cells present. Electron micrographs showed infected cells with 1 to 3 viral inclusions. Intact inclusions contained densely packed icosahedral virions. Dense-staining inclusions, by light microscopy, were seen infrequently and by electron microscopy appeared to be accumulations of membrane-bound material and not viral inclusions
\end{abstract}

Viral erythrocytic inclusion body syndrome (EIBS) was first documented to occur, as a natural infection, in 1982 at Little White Salmon National Fish Hatchery, Cook, Washington, USA, in juvenile spring chinook salmon Oncorhynchus tshawytscha (Leek 1987). Since this observation EIBS has been found throughout Washington and Oregon and in parts of Idaho and California in hatchery-reared salmonids (Piacentini 1989).

The virus, an icosahedral particle 70 to $80 \mathrm{~nm}$ in diameter, has not been replicated in vitro (Piacentini 1989). A method for artificial infection has been developed and used to determine the stages of the infection process. Five stages were identified: incubation, inclusion body formation, cell lysis, recovery and return to normal (Piacentini et al. 1989). In addition Piacentini et al. (1989) demonstrated the effect of water temperature on EIBS; an increase in temperature accelerated the progression of the disease but decreased the disease severity, and horizontal transmission of EIBS was also demonstrated.

The most common clinical sign of the disease is anemia which may vary from mild to severe (Leek 1987). Often EIBS is associated with other diseases such as bacterial kidney disease, coldwater disease and fungus infections (Piacentini et al. 1989). The disease is clinically diagnosed by microscopic examination of stained blood smears for the presence of typical intracytoplasmic inclusion bodies in erythrocytes. The staining method of choice is pinacyanol chloride (Yasutake 1987), although inclusions can also be observed when blood smears are stained by other methods including Leishman-Giemsa (LG) (Yasutake \& Wales 1983).

The purpose of this investigation was to compare morphological changes seen in stained blood cells by light microscopy with those seen by electron microscopy and to determine if erythrocytic inclusions were of viral origin, associated strongly with viral particles, or contained material with no viral association.

Materials and methods. Between April 1988 and April 1989, juvenile chinook salmon (13 to $50 \mathrm{~g}$ ) or coho salmon Oncorhynchus kisutch (22 to $32 \mathrm{~g}$ ) reared at WDF Columbia Basin hatcheries were sampled when they had a high prevalence of intracytoplasmic inclusions in their erythrocytes. Blood was collected from 10 to 12 fish for each of 8 stocks of fish (Table 1).

Wet mounts of blood were occasionally examined in the field using phase contrast microscopy. This method was used to find fish with erythrocytes containing numerous cytoplasmic inclusions. 
Table 1 Oncorhynchus tschawytscha, O. kisutch. Chinook and coho stocks sampled for light and electron microscopic examination

\begin{tabular}{|llcc|}
\hline Hatchery & Species & Brood year & Size \\
\hline Grays River & Coho & 1986 & $32 \mathrm{~g}$ \\
Lewis River & Coho & 1986 & $32 \mathrm{~g}$ \\
Cowlitz & Coho & 1987 & $22 \mathrm{~g}$ \\
Kalama Falls & Coho & 1987 & $23 \mathrm{~g}$ \\
Washougal & Coho & 1987 & $24 \mathrm{~g}$ \\
Klickitat & Spring chinook & 1987 & $23 \mathrm{~g}$ \\
Tucannon & Spring chinook & 1987 & $50 \mathrm{~g}$ \\
Lyons Ferry & Fall chinook & 1987 & $13 \mathrm{~g}$ \\
\hline
\end{tabular}

Fish were sacrificed using MS222, the caudal peduncie severed, and blood collected in heparinized hematocrit tubes. Blood smears were made and the remainder of the blood from the fish dispensed into microcentrifuge tubes. Blood smears were air-dried, fixed in absolute methanol, stained with LeishmanGiemsa stain (LG) and examined by light microscopy. LG was used because it allows for differentiation of cell types and stages of cell development. Blood in the microcentrifuge tubes was centrifuged at $12500 \times \mathrm{g}$ for $5 \mathrm{~min}$ to pellet the cells, the serum was removed, and $2.5 \%$ glutaraldehyde (in Millonig's phosphate buffer solution) fixative was added to the pellet for $30 \mathrm{~min}$. The pellet of fixed cells was then teased away from the edge of the centrifuge tube using a fine point wood skewer to assure complete penetration of the fixative. The glutaraldehyde was removed and fresh fixative applied for $24 \mathrm{~h}$ at $4^{\circ} \mathrm{C}$. The glutaraldehyde was again removed and Millonig's phosphate buffer pH 7.2 was added. Samples were refrigerated until prepared for transmission electron microscopy.

Results and discussion. Examination of wet mounts of blood by phase contrast microscopy showed that cytoplasmic inclusions were easily observed (Fig. 1). Mitochondria usually appeared as thin, elongate rods. However, on end, they appeared round, but generally smaller than viral inclusions. A stained blood smear prepared from the identical fish that was examined using phase contrast had substantially fewer inclusions, indicating that cytoplasmic inclusions and infected erythrocytes may be fragile and possibly destroyed while making blood smears. This may result in an observed lower prevalence than the population actually is experiencing.

After LG staining, infected erythrocytes usually exhibited single, pale blue inclusions; however several small inclusions scattered throughout the cytoplasm, usually in close proximity to each other, were occasionally seen (Fig. 2). Erythrocytes in many stages of development were common, some of which were atypical in size and shape as characterized by spindle-shaped cells, bilobed nuclei and/or nuclear segmentation. In some stocks immature erythrocytes accounted for 50 to $75 \%$ of the cells present, and erythroblasts were occasionally seen. Fish that had fewer inclusions and abundant immature erythrocytes in later stages of development were thought to be recovering from the infection. Degeneration of erythrocytes was also apparent, the cytoplasm was often vacuolated and the nuclei sometimes swollen or pyknotic. Polymorpho-

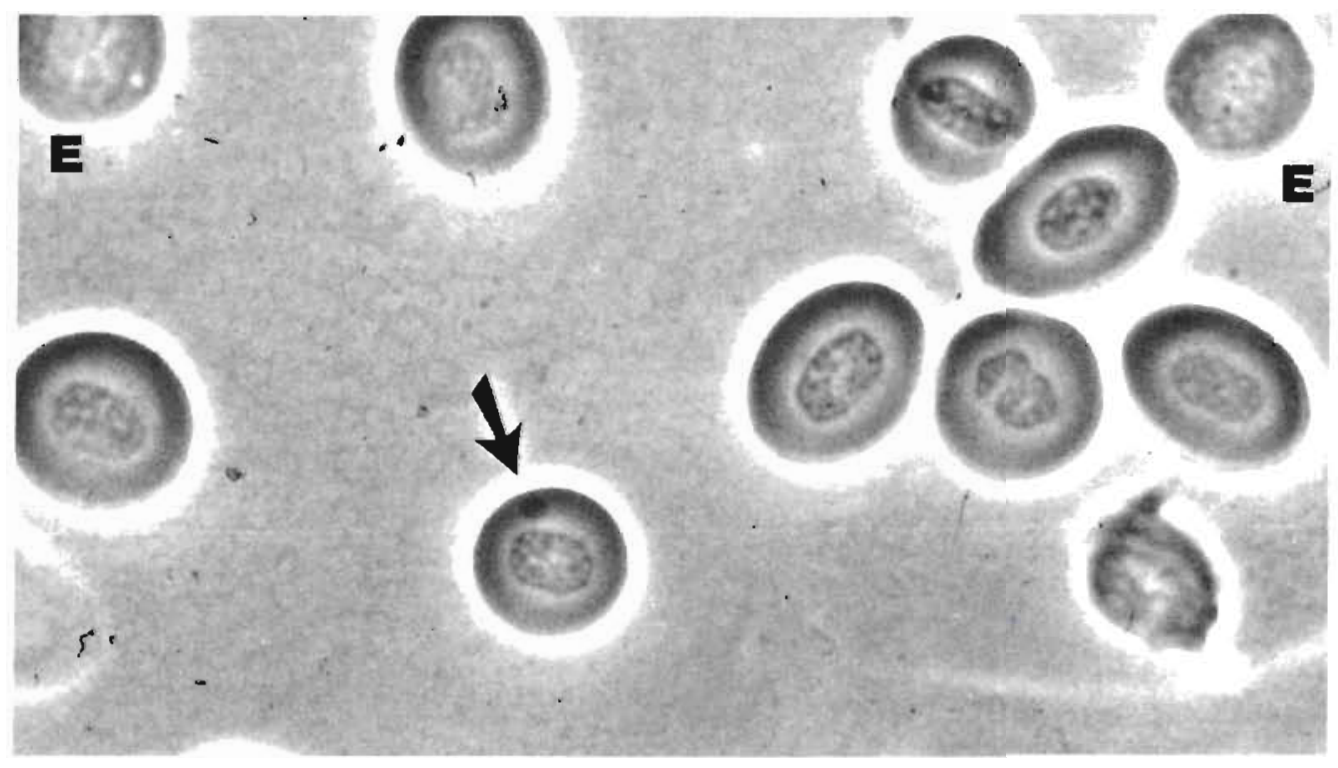

Fig. 1. Oncorhynchus tshawytscha. Wet mount of blood using phase contrast microscopy from Lyons Ferry fall chinook showing erythrocytic inclusion body (arrow) and erythroblasts ( $E$ ) in circulating blood 


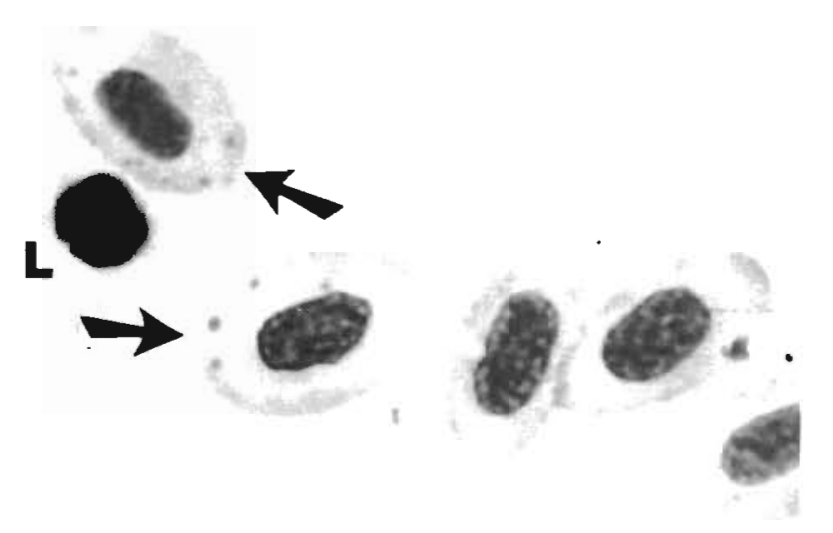

Fig. 2. Oncorhynchus kisutch. Two erythrocytes from Lewis River coho salmon stained with LG that contain small inclusions scattered throughout their cytoplasm (arrows). Note lymphocyte (L) adjacent to one

nuclear leucocytes showed hypersegmentation of the nuclei, and macrophages were common often containing cytoplasmic debris (Fig. 3).

Electron micrographs of blood cells showed infected erythrocytes usually with 1 to 3 viral inclusions per cell (Fig. 4). Occasionally as many as 6 or more were present (Fig. 5). Intact inclusions contained densely packed virions, icosahedral in shape with an electron-dense staining core (Fig. 6). Individual virions measured 70 to $80 \mathrm{~nm}$ in diameter. Microtubules were often present within inclusions, or in close proximity to them (Fig. 7). Virions were often observed within membrane-bound structures and were frequently associated with cellular membranes (Fig. 8). It was not determined if virions were being released from inclusions, or being formed on their membranes. Occasionally, virions were free in the cytoplasm of erythrocytes or had combined within large cytoplasmic vacuoles (Fig. 9).

Degenerate erythrocytes, both mature and immature, were common. Many showed extreme swelling and degeneration of mitochondria resulting in large cytoplasmic vacuoles. However, it was difficult to determine if they had ever contained cytoplasmic inclusions.

By light microscopy, dense-staining inclusions were seen infrequently in the cytoplasm of immature and mature erythrocytes. By electron microscopy these appeared to be accumulations of membrane-bound material, and not viral inclusions (Fig. 10). These 'false' inclusions should not be difficult to distinguish from viral inclusions in stained preparations because of their dense, dark-staining characteristics.

Evaluation by light and electron microscopy typically showed 1 viral inclusion per infected cell. Samples containing cells with multiple inclusions (more than 3) by electron microscopy correlated to the light

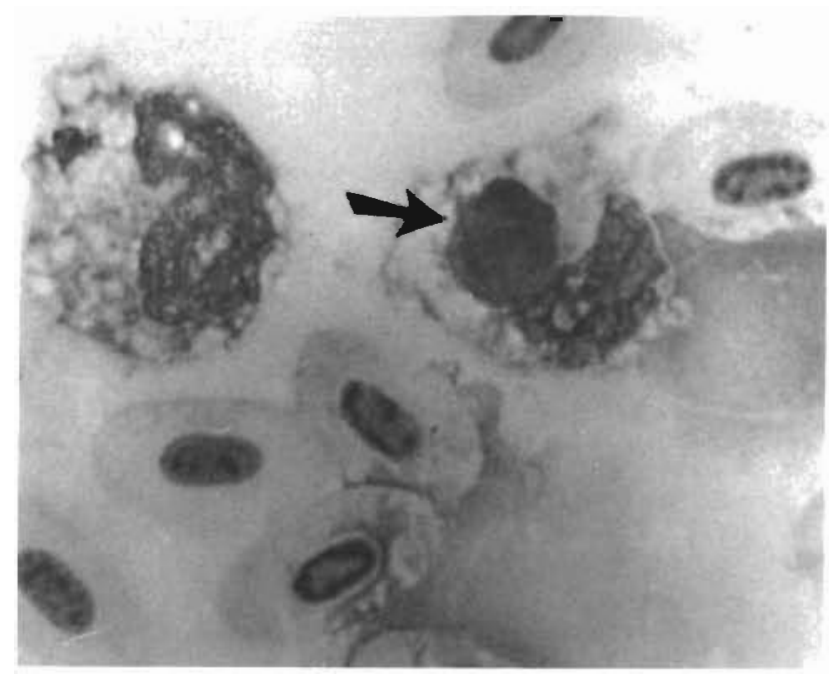

Fig. 3. Oncorhynchus kisutch. Two macrophages. Note large degenerate nucleus (arrow) that has been engulfed by cell on right. From Lewis River coho salmon stained with LG

microscopy observations of multiple inclusions of varying sizes, 0.4 to $1.6 \mu \mathrm{m}$, per cell.

We have shown that typical erythrocytic cytoplasmic inclusions in EIBS infected fish were of viral origin. Samples that had atypical dense staining inclusions by light microscopy had inclusions by electron microscopy that appeared to be degenerate membranebound material.

Acknowledgements. We thank Andy Blixt for the electron photomicrographs and Pat Chapman for assistance with sampling and editorial review, Beth MacConnell for assistance with developing a whole blood preservation technique and coordination and transport of samples, John Morrison for phase contrast photographs, and Bob Rogers and Dr Jim Winton for editorial review. We also acknowledge Bonneville Power Administration for providing funding for this work.

\section{LITERATURE CITED}

Leek, S. L. (1987). Viral erythrocytic inclusion body syndrome (EIBS) occurring in juvenile spring chinook salmon (Oncorhynchus tshawytscha) reared in freshwater. Can. J. Fish. Aquat. Sci. 44(3): 685-688

Piacentini, S. C. (1989). Erythrocytic inclusion body syndrome: a viral disease of salmonid fish. Master thesis, Oregon State University, Corvallis

Piacentini, S. C., Rohovec, J. S., Fryer, J. L. (1989). Epizootiology of erythrocytic inclusion body syndrome. J. aquat. Anim. Hlth 1: 173-179

Yasutake, W. T., Wales, J. H. (1983). Microscopic anatomy of salmonids: an atlas. U.S. Dept. of Interior. Resource Publication 150

Yasutake, W. T (1987). Standardization of stain used for diagnosing erythrocytic inclusion body syndrome (EIBS). Fish Health Section/American Fisheries Society Newsletter 15(2): 7 

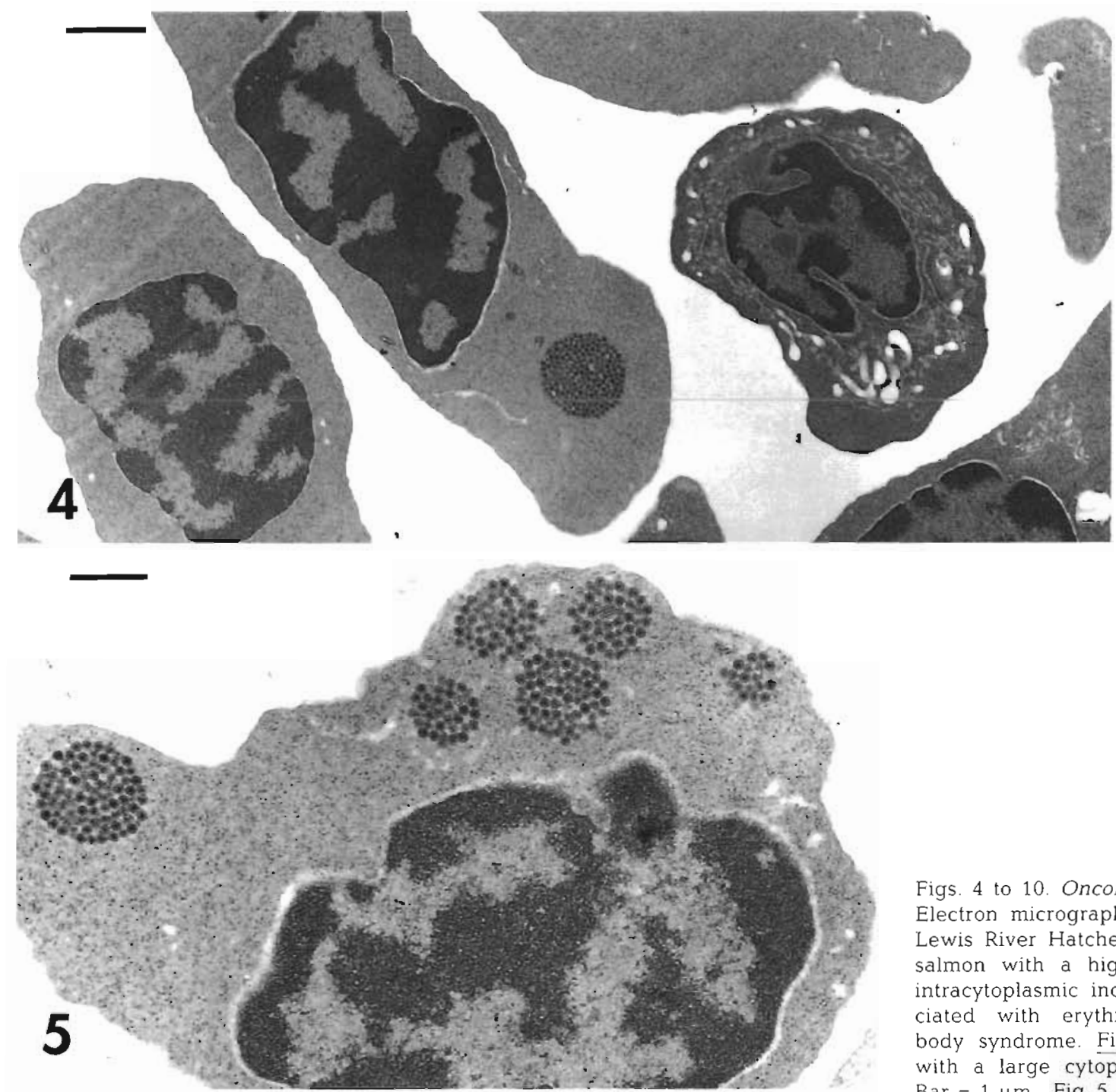

Figs. 4 to 10. Oncorhynchus kisutch Electron micrographs of blood from Lewis River Hatchery yearling coho salmon with a high prevalence of intracytoplasmic inclusions, as associated with erythrocytic inclusion body syndrome. Fig. 4. Erythrocyte with a large cytoplasmic inclusion. Bar $=1 \mu \mathrm{m}$. Fig. 5. An atypical erythrocyte shows 6 viral inclusions within the cytoplasm. Bar $=0.5 \mu \mathrm{m}$. Fig. 6. Membrane-bound intact inclusion. Bar $=0.16 \mu \mathrm{m}$. Fig. ?. Erythrocyte containing several small and one large viral inclusion. Note microtubules in large inclusion, also virions are dispersed throughout the cytoplasm of the cell. Bar $=0.5 \mu \mathrm{m}$. Fig. 8. Two typical inclusions and one with viral partıcles either being formed on the membrane (arrow) or being released into the cytoplasm of the cell. Bar $=0.26 \mu \mathrm{m}$. Fig. 9. Erythrocyte in the center contains virions within large vacuoles. Note degenerate mitochondria (arrow) and virions in cytoplasm of cell above. Bar = $0.64 \mu \mathrm{m}$. Fiq. 10. Atypical inclusion that appears to be membrane-bound degenerate material. $\mathrm{Bar}=0.2 \mu \mathrm{m}$ 

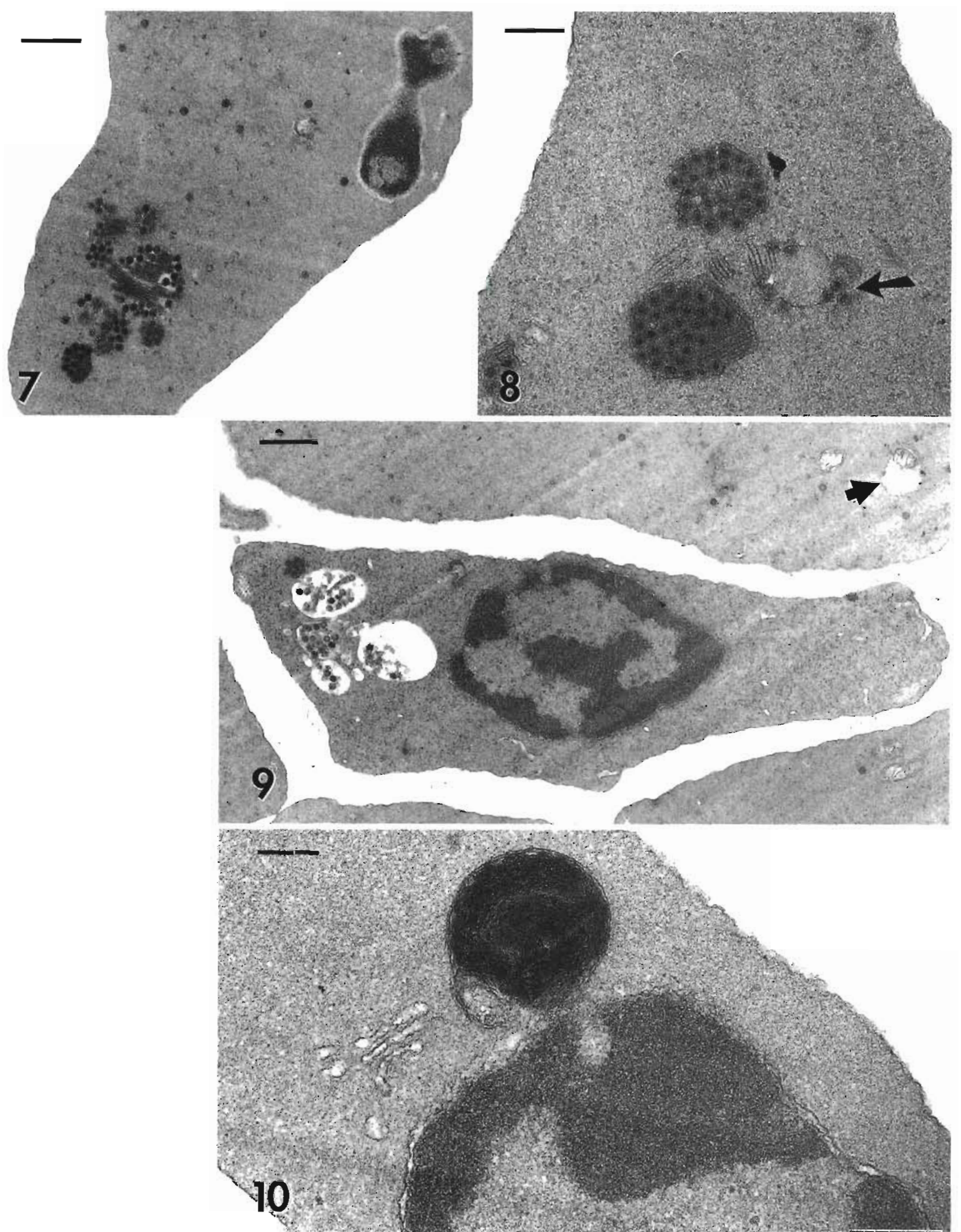